\title{
Why Single-Sex Schools? Discourses of culture/faith and achievement
}

\begin{abstract}
This paper is developed from a study carried out to explore factors influencing the choices of a range of stake-holders in a multi-ethnic urban community - students, parents, teachers, community representatives - with regard to single-sex schooling. The paper discusses competing perspectives underpinning the focus of the study. Recent legislation in America approving single-sex schooling (Hutchison Amendment in June 2001), and increased provision of single-sex classes in UK and elsewhere have augmented the debates around single-sex education and achievement. However, another important but less explored aspect is association between single-sex education and culture/faith in certain communities/countries. In today's multi-ethnic multi-faith societies, it is highly significant to look at schooling preferences from the perspectives of different groups and communities for the purposes of responding to their needs and expectations. This paper extends the debate by discussing the impact of culture and faith on school choices with regard to single-sex versus co-educational schooling.
\end{abstract}

\section{Why Single-Sex Schools? Discourses of culture/faith and achievement} By

\section{Saeeda Shah, University of Leicester}

\section{With}

\section{Catherine Conchar, Nottingham City Children's Services}

Single-sex education is a historical phenomenon. Traditionally, single-sex education has been in the form of boys-only schools (Ivinson and Murphy, 2007) invoking feminist critique in the modern and post-modern eras with regard to equal opportunities and female marginalisation (Deem, 1984; Weiner, 1994). In the twentieth century, growth of co-educational institutions led to debates about strengths and weaknesses of single-sex versus co-educational schools. A variety of explanations have been offered by researchers supporting competing positions, but like other contending debates 'the explanations have often been guesswork, prejudice or attempts to support particular theories' (Tomlinson, 1991, p.121). There is no study which can claim to have controlled every other variable to fully investigate single-sex or co-education factor (Smithers and Robinson, 2006). Smithers and Robinson (2006) offer a detailed review of literature, quoting studies from Australia, America, Canada and the UK which discuss the impact of single-sex and co-educational schools, and separate classrooms for boys and girls, on academic achievement, subject choice/s and personal/social development. They emphasise that the evidence is inconclusive to support the effect of single-sex provision on education or indeed educational achievement: 
Without clear general findings, deciding whether to mix or separate the sexes for education has to be a matter of judgment. (Smithers and Robinson, 2006, p.31)

A dominant assumption among supporters of single-sex education is that it contributes to achievement as it relieves students from perceived conflict, pressures, tensions, and temptations (Riordan, 2004). Riordan is emphatic that single-sex schools work for girls and boys, women and men, whites and non-whites; but he also admits that the beneficial effects of single-sex schools are greatest among certain groups such as Black or Hispanic females from low socioeconomic homes (Riordan, 2004). Salomone (1999) lists many theories in favour of single-sex school, but explains that "effects of single-gender schools have been greatest among students who have been disadvantaged historically - disadvantaged minorities, low and working class youth and females (so long as the females are not affluent)' (pp.283-84). Extensive debates in the USA before and after The Hutchison Amendment in June 2001, which made single-sex education unambiguously legal ${ }^{1}$, produced substaintial literature in this area. However, 'Single-sex education [remains] a complex web of unanswered questions' (Salomone, 1999, pp.275).

This paper argues that single-sex education needs to be explored and analysed in the wider social context in the backdrop of the values and beliefs of the school community. It draws from a recent research project carried out in Nottingham City ${ }^{2}$ to debate single-sex schooling with particular focus on ethnic minorities, who were a high majority because of the specific demographics of the research context. The study explored views and perspectives of diverse local communities and stakeholders with regard to single-sex schooling, looking into educational, social, cultural and religious concerns. The project was designed to ensure widespread consultations with the local community and all concerned. In addition to the teachers, parents/carers, community leaders, faith groups and others, a large number of students and young people from mixed schools, faith schools and single-sex schools participated in the study.

\section{The Study}

The study was designed to seek the views and perspectives of the diverse range of stakeholders regarding single-sex schooling in a specific multi-ethnic urban context 
(Single-Sex Education Report, 2007). In view of the potential diversity of the expected research participants it was decided to deploy a number of varying information-gathering strategies. Barriers of access, language, writing ability, internet access, cultural constraints, gender and others were recognised, and a range of methods and formats were used to collect data. This included two questionnaires one for adults and one for young people (both administered on paper and online), consultation events, focus groups and interactive voting.

Semi-structured questionnaires were the main tool for data collection, followed by focus group discussions with purposively selected groups, and 'interactive voting' with members of the local Youth Council (age 11 to 18). One consultation event was organised prior to data collection, to discuss the project format and content of the first questionnaire with the diverse stake holders and the wider community. Over 245 local community groups and all members of Nottingham City's Race Achievement Forum were invited to this meeting, which was attended by 48 people - some participants chose not to register their attendance for political reasons. The majority of attendees were from minority ethnic groups and it later emerged from other conversations that in general the White British people did not see single-sex education as a key issue.

The sample for the study included staff, students, parents/carers and governors of the single-sex comprehensive school, staff and parents/carers from ten feeder primary schools, students from twenty other secondary schools, members of the Youth Council, and representatives of community organisations/groups. An explicit attempt was made to include those people in consultations who were pertinent to the study, and those who traditionally lacked voice, particularly those previously defined as 'hard to reach', by providing appropriate mode, grouping and environment to voice their opinions. The paper draws on the data collected from:

1. Questionnaires (total questionnaires served, 5670)

a. Adult responses 1045 (on paper) +156 online

b. Young people responses 159 (on paper) +22 online

2. Twelve focus groups with mature people: six women only, four men only, and two specific groups 
3. Ten focus groups with young people: six groups (both single-sex and mixed) from four schools, three youth groups, and the Nottingham City Youth Council group.

4. Two open community consultation events

The data were rich and highly complex, raising multiple concerns. It pointed to the complexity of the issue and contending perspectives. The findings highlighted that single-sex education was important to certain ethnic and faith communities; however, support for this preference varied with gender, age, and heritage factors. Second, a dominant assumption among supporters of single-sex education was that it contributed to achievement by relieving students from perceived tensions, temptations and pressures. This paper debates the significance of single-sex education as emphasised by some groups and discusses the factors underpinning their perceptions.

\section{Single-Sex Education: a preference?}

Single-sex schooling emerged as 'very important/important' to $58.6 \%$ adult respondents while $39.5 \%$ stated that it was either 'not very important' or 'not at all important' to have a single-sex school. A key finding was that single-sex education was considered more important by male respondents. While $51.5 \%$ women said that single-sex education was 'very important'/'important', reflecting a relatively divided opinion, $69 \%$ of male respondents stated that single-sex education was 'very important'/'important', raising some important questions. First, does this favouring of single-sex education reflect the desire to have single-sex education only for girls, or for both boys and girls? Second, does it indicate a genuine educational need or is it the reinforcement of gendered division and social control? The data signal that support for single-sex education in this case is for girls-only provision, thus pointing to sensitive and complex gender issues such as stereotyping, social patterns and gender roles. This was confirmed in the focus groups where male supporters of singlesex education talked about need for girls-only schools, while female supporters of single-sex education explicitly maintained that single-sex schooling should be for both girls and boys.

A complex picture emerges when responses are further analysed by religion/belief, ethnicity, and heritage. About $90 \%$ of all Muslims, $27 \%$ of Christians, $28 \%$ of No 


\begin{tabular}{|l|l|l|l|l|}
\hline Age/Gender & For & Neutral & Against & Total \\
\hline Boys (11-18) & 0 & 0 & 4 & 4 \\
\hline Men & 9 & 0 & 0 & 9 \\
\hline Women & 3 & 0 & 3 & 6 \\
\hline Youth Centre & 7 & 1 & 0 & 8 \\
\hline Total & 19 & 1 & 7 & 27 \\
\hline Religion and 52.9\% of others stated that single-sex education was 'very
\end{tabular}

important/important', evidencing a high preference for single-sex education among Muslims (Shah, 1999). An overwhelming majority of all respondents supporting single-sex education, however, were from minority ethnic groups belonging to the Muslim faith. For $69.6 \%$ White British respondents single-sex education was 'not important'/'not at all important', while among other minority ethnic groups for example, only $13 \%$ of Pakistani, $4.8 \%$ of Kashmiri, $1.8 \%$ of Bangladeshi, $8.6 \%$ of Arab and $0 \%$ of Afghan respondents said that single-sex education was 'not important/not at all important', reflecting the association between faith, ethnicity and single-sex education.

The respondents were also monitored by heritage (heritage for the purposes of this study is defined as born in the UK/not born in the UK). According to the research findings, single-sex education received less support from British-born ethnic minority people. Single-sex education was identified as 'very important/important' by $43.6 \%$ of respondents born in the UK and $60.6 \%$ of those not born in the UK, thus indicating that a higher number of those not born in the UK favour single-sex education. This pointed to changing attitudes and the impact of societal culture (as compared to parent- or country-of-origin-culture), and environment on educational preferences. Even faith had less impact here as only $32 \%$ of Muslim young people stated that they would consider going to a single-sex school given the choice. There were interesting variations not only across different ethnic groups but also within ethnic groups in terms of age and gender, as shown in Table 1, presenting responses from on ethnic $\operatorname{group}^{3}$ :

Matrix Indicating Responses for/against Single-Sex Education from one Ethnic Group 
Table 1 shows that very young boys oppose single-sex schools, and about half of the female respondents from this ethnic group are also not in favour of single-sex education. Those who appear to support single-sex education are men and mature youths, inviting questions such as: is the younger, British-born generation more in favour of co-educational institutions? Why do men support single-sex schools so overwhelmingly - particularly for girls? Is it a 'discourse of control' over women? Is it a religious obligation? Is it a cultural requirement? The study raises many questions and this paper attempts to engage with the relevant debates to explore these issues.

\section{Why Single-Sex Education?}

A range of arguments are offered in favour of single-sex schooling by its proponents (Salomone, 1999). The primary concern is generally an environment conducive to better educational performance and achievement (Weiner, 1994), which this study also confirmed. Some respondents, however, highlighted cultural/faith dimensions, claiming that 'Parents may choose a single-sex school purely because it is single-sex, which is appropriate in their faith/culture, rather than because of the quality of the school'. Nevertheless, the majority were of the opinion that they would choose a school that attends to the cultural/religious needs of the learners, emphasising cultural/faith dimensions but not necessarily single-sex schooling. Question three in the adult questionnaire asked 'what is most important to you?' listing the following options:

1. A School that considers my Child's Religious/Cultural Needs ...

2. A Single-Faith School

3. A School that Promotes Diversity ...

4. A Single-Sex School

5. Other

An overwhelming majority ticked the first and the third options as the most important, which indicated that single-sex schools might not be a favoured option if children's religious and cultural needs are considered, and if diversity is promoted through an understanding of different cultures/religions (Merry, 2007). This draws attention to the serious issue of what schools and school leaders need to engage with to manage diversity in multi-ethnic/multi-faith Britain (Shah, 2009; 2006a). Responses to a 
similar question in the young people's questionnaire reinforced the earlier findings that the main priority of young people is an inclusive, democratic and equal opportunities environment rather than a single-sex or single-faith school. Only 27 out of 181 young respondents ticked the single-sex option, which was the lowest score for any category in this question. There was overwhelming support for those schools which would provide good education (140), equal opportunities (143) and equal participation (103).

The focus group data also reflected a similar spread of responses. The comments of the participants who supported single-sex education were collated under four main headings: education, culture, religion/belief and social. A large number of participants believed that single-sex schools provided a 'better learning environment' arguing that 'more focus [is] on education rather than the opposite sex', and complained that 'teachers often favour one gender over another in their teaching in a mixed school'. Many drew attention to 'private sector single-sex schools [that] enjoy high profile and achievement'. Another perspective supported single-sex schools as a cultural/religious requirement claiming that 'in Muslim culture girls are not allowed to go out with boys, which is not a problem in a single-sex school'. Many Muslim research participants emphasised single-sex schools as a religious requirement, while others believed that 'girls feel comfortable and at ease' and are 'more safe and secure' with 'reduced risk of sexual temptation/teenage pregnancy' in girls-only schools.

Some of these comments are reflective of a perceived threat to religious values of the Muslim faith community (Griffin, 2006). Muslim parents expressed concerns regarding co-educational provision, particularly for their girls and specifically during teenage years (Bemmelen and Vliet, 1985). There was, however, an acknowledgement that limiting young people to single-sex institutions had a negative impact on their social skills. Although the majority of the total participants in the focus groups supported single-sex education, there were strong and explicit reasons offered by many, particularly women and young people, in support of co-education to prepare young people for 'the real world'.

Many research participants suggested a compromise by proposing that the schools should be co-educational but some activities/subjects should be taught in single-sex classes, and separate spaces should be available for girls and boys for certain 
purposes. This draws attention, for example, to recent experiments with single-sex subject classes which are discussed in some detail in the next section to explore their significance towards achievement.

\section{Single-Sex Education and Achievement}

A high majority of Muslims participating in this study and a clear majority of all participants favoured single-sex education. A common perception was that students in a single-sex environment are high achievers. Feminists have argued that single-sex schools/classes could provide a liberating experience for young girls contributing to positive self-concept and subject choices by providing a more supportive environment (Smithers and Robinson, 2006). Kenway et al. (1998) posit that 'Single-sex classes for girls may also act as a nurturing emotional refuge' (p.150), pointing to the potential of single sex institutions to offer equality in an unequal world. Riordan (2004) argues that single-sex institutions enhance achievement in the case of marginalised groups. Research, however, is inconclusive in this regard as confirmed by available literature.

Another aspect is related to behaviour and self-concept. In a study from Northern Ireland, Granleese and Joseph (1993) deployed a domain specific self concept measure in their study of girls from one single-sex and one co-educational secondary school. Girls at the single-sex school were less critical of their own behavioural conduct than girls in the mixed school. This lack of criticism was the single best predictor of global self-worth in the all-girls' school. The data for this study also highlighted similar observations, hinting at factors such as relaxed attitudes, freedom to dress in whatever way the girls prefer, less stress about personal appearance and that of others etc.

Initially purported by feminists with regard to girls' education (Weiner, 1994), support for single-sex education currently also underpins the recent government policy towards boys-only teaching provision with the perceived expectation to improve boys' achievement in schools. Arguments for boys-only schools/classes claim that boys have less distraction in a boys-only class and can concentrate better on studies. This has led to experimentations of single-sex classes in many co-educational schools in the UK. The introduction of single-sex classes within co-educational schools is a strategy adopted by some schools to enhance the learning experiences of 
either the girls or the boys, depending upon the educational climate at the time. Jackson (2002) explores the value of introducing single-sex classes within coeducational schools, drawing upon the perspectives of girls and boys involved in one such initiative. The research concludes that girls-only classes may have positive effects for girls, but there was no evidence of any positive effect on boys' achievement (Jackson, 2002). Barker's study (2002) of single-sex classes of maths and sciences in a middle school also corroborates this evidence, claiming that the single-sex environment contributed to girls', but not boys' feelings of empowerment, peer support and positive self-concept. Lee and Lockheed's study (1990) of 1,012 students in ninth-grade Nigerian public schools measured achievement in mathematics. Girls in single-sex schools outperformed girls in mixed-sex classes in mathematics, while boys in single-sex schools did the opposite even after the study had been adjusted for substantial differences in student background, school resources and teacher attitudes.

Harker and Nash (1997) used data gathered in a longitudinal study of more than 5,000 eighth-grade students in New Zealand that was controlled for individual characteristics (such as socioeconomic status) and school type. As with other studies, the researchers confirmed statistically significant differences in favour of girls at single-sex schools. After applying controls for ability levels and for social and ethnic backgrounds, however, the differences disappeared. Harker (2000) used data from a longitudinal study of 37 schools and from the Ministry of Education National Database to explore in detail the relative achievements of girls in single-sex and coeducational schools, with careful controls for the student population differences at the two types of school. He concluded that when such controls are exercised, the apparent differences between the two types of school were reduced to non-significant.

Harker (2000) explored gender differences in achievements at a variety of levels in secondary schools in New Zealand. Gender differences were shown in relation to English, mathematics and science, but the pattern was not consistent across year levels in the senior school. He confirms that research findings are ambiguous concerning the effects of single-sex schools on girls' achievement. In many studies where outcomes initially suggested that teaching within a single-sex environment was more conducive to girls than boys, any differences between the two sexes diminished 
once the findings were adjusted for socio-economic or ability variables (Harker, 2000).

It is argued that single-sex teaching has the potential to raise achievement levels in some contexts but that this potential can be realised when differential teaching approaches are systematically planned and explicitly implemented, monitored and evaluated. Younger and Warrington (2002) studied single-sex teaching in a coeducational school where single-sex teaching had been the norm since the school was established in the early 1970s, and found that the relative improvement levels of both girls and boys over time were similar. Interviews with staff and students, and analysis of patterns of classroom interactions, suggested that both girls and boys benefited from having their own learning space, although there were issues about the reintegration of students, particularly boys, when mixed lessons were provided in the foundation subjects in years 10 and 11 (Younger and Warrington, 2002). This concern over reintegration was expressed in the focus groups for this study, particularly by the young people and the female participants and is discussed later in this paper.

In terms of single-sex schooling and its association with achievement, there is no conclusive evidence. It is argued that 'for' or 'against' stances which shape popular literature on single-sex education can be misleading because assessments of singlesex education's success or failure are linked to multiple factors such as institutional goals and ethos, indicators of success used, historical context and status of school, student selection processes, and others. Historically single-sex schools have been prestigious and private and are held in greater esteem because they generally have selective admission policies to screen the large number of applicants. According to Riordan (1990) policies in single-sex schools that emphasize the academic side of educational activities explain the higher score. If the school factor is controlled then there is no consistent evidence of differential achievement regarding girls and boys in single-sex or co-educational schools/classes. LePore and Warren (1997), using data from the National Educational Longitudinal Study of 1988, found that boys in singlesex schools did not increase their test scores any more than boys in co-educational schools and that girls experienced no statistically significant positive effects of singlesex school enrolment. Another recent project in a Pembroke school experimented with organising mixed gender groups in one half-year and single-gender groups in the 
other half year for English, mathematics, science, history and technology (Research Report, 2006). The research concluded that the data showed no consistent or appreciable impact on attainment in the different groups.

Research is inconsistent in its assessments of whether single-sex education is 'better' than co-education for girls or boys or both. Some research supports the view that single-sex contexts foster less stereotypical views of subjects and that girls view the single-sex classroom as more conducive to learning, but research fails to confirm significant gain in girls' achievement in the single-sex classroom (Lee and Marks, 1990). The interim findings report (The Standards Site, 2006) from a DfES commissioned team of educational specialists working with schools around the country, makes some similar points:

- Conflicting evidence over whether examination results are better for pupils taught in single-sex groups.

- Pupils are almost always in favour of single-sex groupings, especially girls.

- Teacher opinion is often divided, but most acknowledge greater levels of participation in lessons and increased confidence amongst both sexes.

- All-boy sets can be difficult to manage, although teachers often feel that behaviour is better in single-sex groups.

Another recent study (Sullivan, 2006) confirms that empirical findings on the questions of single-sex schooling and self-esteem, self-concept and participation in gender-atypical subjects, have been mixed. Some advocates of single-sex schooling for girls have argued that girls' self-esteem is better fostered in a single-sex environment, as boys tend to dominate in a mixed environment. Some research does suggest association between single-sex schools/classes and achievement, feelings of empowerment, sense of comfort and positive self-concept, and highlights girls' preference for single-sex groupings. Many studies, however, have different findings. Sullivan (2006) quotes studies arguing that single-sex classes within co-educational schools provide mixed results and that research is inconclusive.

In the present study, parents/carers, particularly males from some ethnic/faith groups, do voice a preference for single-sex education for various reasons including educational achievement and undivided concentration on studies. Responses from 
young people, however, were more in favour of co-education, with separate classes for PE \& PSHE and separate personal spaces for boys and girls. This may not suggest implications for educational achievement as such, but its association with a sense of comfort and an 'infiltration free zone' (Haw, 1998) cannot be argued with. This can be a reference to gendered role socialisation transferred from homes and homecultures to educational spaces with hidden implications for girls' comfort levels in coeducation and with implications for their holistic development. This aspect gains particular significance in the light of current governmental policy on the Every Child Matters Agenda (Education Act, 2004) where schools are being heavily encouraged to extend their engagement with children and young people beyond the traditional remit of academic achievement. There is a growing requirement to look at the needs (complex or otherwise) of the 'whole' child/young person (Merry, 2007): namely health, making a positive contribution, economic well-being, safety and enjoyment (Education Act, 2004). Is a single-sex environment more conducive to satisfying these needs in the case of girls? Do girls feel more happy, relaxed and comfortable in a single-sex environment? Is it an issue of power relations between the sexes, transferred from the wider social stereotyping, affecting girls' experiences of coeducation? If so, what implications does this have for educational engagement and achievement?

In many studies exploring ethnic educational achievement Muslim girls emerge as a high achieving group compared to Muslim boys (Abbas, 2006; Ahmed, 2001; Birmingham City Council, 2005; DFES, 2004). Is this contradictory evidence or does this mean that girls work harder to break out of the 'glass ceiling'? The studies point to socio-cultural structures among Muslim communities where girls/women engage with education with higher commitment because this is perceived as a way to progress compared to boys/men. A complex picture emerges here, pointing to multiple factors impacting on Muslim girls' performance, and single-sex schools can be just one of these.

\section{Single-Sex Education, and discourses of faith, culture and gender}

Sex-segregation has remained a conspicuous feature of Muslim societies, favouring single-sex institutions. The rhetoric emphasises it as an Islamic injunction. It is, however, a relative concept recommended so far as it is essential to maintain the 
social fabric of a Muslim society with its specific discourses of family and sex. Some Muslim communities or individuals perceive sex-segregation as a religious requirement, but it is not supported by religious texts (Shah, 1998). The Quran recommends preferred demeanours for men and women ${ }^{4}$, but it does not command sex-segregation, and particularly not with reference to teaching/learning situations. Sex-segregation as defined by the Quran is a part of a particular educative programme for men and women and is linked with the discourses of sex and family in Islam. It aims at creating a non-threatening environment to ensure equal participation of men and women in public as well as in private. It is to facilitate this participation, and not for the purposes of marginalising women. The preferences for appropriate dress and behaviour code put forward in the Quran for mixed contexts indirectly negate sexsegregation. The Prophet Mohammed himself taught men and women, together at times, in the mosque of Medina (Al-Hibri, 1982; Mernissi, 1991; 1993). His wife Ayesha continued to teach men and women in the same mosque. Therefore, sex-segregated institutions can not be mandatory in Islam as they are not explicitly validated either by the Quran or the Sunnah.

Segregatory tendencies in Muslim societies, however, can be attributed to Islamic notions of sex, sexuality, and morality. Sexual activity is highly proscribed and circumscribed in Islam and any sex outside marriage is strictly forbidden (Al-Ghazali, 1995). Chastity is emphasised with a promise of 'forgiveness and reward' to 'men and women who guard their chastity' (Quran, 33:35). Muslim parents demanding singlesex education for girls can be apprehensive of the wider social context within which education is provided and the popular notions of sex, morality and marriage which are active in the host society (Shah, 1998), as reflected in the data collected during this consultation. Many Pakistani immigrants now settled in Britain continue to send their young daughters back to Pakistan to be educated in a single-sex context, incurring the cost of air fares and maintenance for many years because of this perceived threat to their 'moral code' by schools offering co-education. 'Asian parents are very protective of their daughters because of their perceptions of English society's problems with drugs, alcohol, and undue emphasis on sex' (Ali, 1996, p.411). Distance can be and often is maintained from the indigenous society and its culture outside educational institutions, but schools are a different matter where 'protecting their daughters' may become a challenge if it is co-education. 
Another important factor in deciding an appropriate environment for their children's education is the dominant discourses within extended family and community (Shah, 2008). Islamic teachings and injunctions regarding the immediate and extended family, and other Muslims, for example, are reinforced by the local patterns of behaviour concerning family and bradari (Bagguley and Hussain, 2007; Shain, 2001; Tyrer and Ahmad, 2006). It becomes a doubly emphasised phenomenon, deeply embedded in ideology and culture, creating a network of relationships that is complex, fluid and encompassing, impacting on decision-making in many matters which would be considered personal in individualistic societies. Hence personal decisions like sending girls to single-sex or co-education schools may often be decided under direct or indirect pressures of extended family and community. Even when a particular family or parents may not have any preference for single-sex schooling, they may choose the single-sex option in submission to the pressures from the extended family, 'bradari', or community (Shah, 1998; Shaw, 1988), as submission to the collective sub-culture is essential for survival within bradari networks (Sharma, 1980).

Arranged marriage is another powerful discourse influencing parental preference for single-sex education within certain communities. Co-education is perceived as a threat to arranged marriages as it may open other venues of thought and options. The girls in co-education may choose to exercise personal choices, defying collective decisions. The assumption appears to be that girls-only schools provide 'infiltration free zones' in which to educate the girls, without posing any serious threats to cultural traditions with regard to arranged marriage and family networks. Studying or working in a mixed-sex environment after marriage does not emerge as a serious issue (Shah, 1998). A marriage is perceived as a collective rather than an individual matter. In fact, arranged marriages are not always simply organised by parents, but are often decided under huge pressures from extended families and bradaris. In the collective cultures of these societies, underpinned by the network of arranged marriages, parents often have difficulty in questioning bradari authority (Basit, 1995).

The issue of single-sex schools has complex socio-cultural dimensions, specifically with regard to girls' education, not just for Muslims but for many other communities and societies. It is often used as a political mode of ordering roles and practices. Single-sex institutions provide 'institutionalised boundaries' (Mernissi, 1985, p.137) and 
highlight the technologies of power (Foucault, 1980) wielded for exercise of control over cultural practices. For some ethnic/faith communities such as Muslims, Asians and others it is linked to concepts and practices such as izzat (honour), arranged marriages and family networks. Izzat in its simplest form means respect and honour but in the case of women, a complex discourse of izzat becomes active which is gendered, familial and social, and which as such has no legal or religious validations. It imposes constraints on women by making them responsible for izzat (Anwar, 1978; Shah, 1999; Weiss, 1994), thus giving it a gendered description, which underpins the demand for single-sex education for girls in particular, preparing them for a specific social role. The consistency of such cultural patterns of behaviour is confirmed by the majority of Muslim respondents participating in this study demanding single-sex education for girls, although a few voices are also heard voicing a challenge to the dominant discourse.

Roles are social constructions, be these domestic roles or public. In the case of Muslims, social roles are often enmeshed with religious roles to the extent that to disentangle and identify the discourses is problematic (Shah, 2006b). Socio-cultural norms and discourses determine gender roles and practices in the private and the public areas and define the sites. Women are to be restrained to the private/domestic domain which requires limiting their movement to women-only space, in this case single-sex schools. For a woman it would be a violation of family izzat to move into 'male domains' and here izzat as a technology of power serves its purpose: control of women. Interestingly, in the first Muslim society of Medina, during the Prophet's lifetime, two major public sites were the mosque and the battle-field, and Muslim women participated in both (Ahmed, 1992; Mernissi, 1991; Smith, 1987). The technologies to restrain or confine women illuminate patriarchal modes of ordering gendered power relations, which have a relevance to the Foucauldian argument that discourses are never free of history, power and interests (1980, p.131).

If sex-segregation is not a religious requirement in essence, then why did a high majority of Muslims participating in this study favour single-sex institutions? This draws attention to more complicated and sensitive issues related to cultural values and interpretations of faith as located in cultural contexts. The inner diversity of Muslim $U m m a h^{5}$ is obvious from Muslim demographics across the world. There are fifty-two 
Muslim states, in addition to huge Muslim population living in secular countries all over the world, including India, China, Africa, and Western countries. This raises questions regarding the impact of cultural and faith systems on educational choices, particularly the implications of these experiences for educational choices.

\section{Conclusions}

Single-sex education is a complex and sensitive issue. Its impact on the educational achievement of learners (boys or girls) is just one facet of the debate. Equally significant are cultural, social, political, economic, religious and other dimensions of the issue (Skelton et al., 2007). Any one or combinations of these elements may become significant for achievement in a particular situation at a particular time. The two major themes that emerge from this study are, first, a perceived link between educational achievement and single-sex schooling, especially among male respondents; and second, impact of culture/faith in demanding single-sex schools specifically for girls.

As discussed above, association between single-sex education and achievement is inconclusive, reflected in contending debates around issues such as:

- What does achievement mean in itself?

- Is it a score or a grade?

- Is it holistic development of the students as put forward in the Every Child Matters agenda?

- How can association between single-sex education and achievement be measured in the face of multiple variables such as school type, resources, locality, learners and their personal/social positioning, to name just a few?

Even the studies which try to control various factors are extremely tentative in their findings and hasten to explain them as context/factor specific (Harker, 2000; Harker and Nash, 1997; Riordan, 2004). A feminist argument in favour of single-sex schools has been that being in a women's environment is both empowering and nurturing (Weiner, 1994). Gender stereotyping and bias are seen as major factors in influencing teaching/learning where girls might receive less attention and fewer opportunities compared with boys. Furthermore, girls from certain ethnic/cultural/economic backgrounds might feel inhibited in mixed-sex settings, becoming less motivated to 
engage in classroom activities, which in turn might affect their educational performance. A counter argument, however, supported by many of the younger participants in this study is that girls-only institutions are a departure from the 'real world', creating a cloistered environment in which women who are unable to compete with men receive special attention, essentially claiming that these educational settings do not enable them to learn social skills or be prepared for real life situations/activities.

Another side to this debate on single-sex education is its culture-defined nature. A consistent theme projected by the participants in this study was that single-sex education, particularly for girls, was 'important'/‘very important' for certain ethnic/faith groups, namely Muslims including Arabs, Bangladeshis, Kashmiris, Pakistanis as well as others, which emphasises the impact of beliefs and culture on these choices or preferences. As discussed in the relevant section above, however, there is clearly less support for single-sex education from the very young and British-born and also from women/girls within these same faith/ethnic groups. This is a significant finding which, in part, highlights the need for specific educational provision for certain ethnic/faith groups, a factor which needs to be acknowledged by the policy-makers for the purposes of decision-making, but at the same time highlights variations in choices with regard to gender, age and changing social structures. The findings also unpick intragroup variation of opinions pointing to power relations with regard to gender in certain social structures, emerging resistance to those structures, and changing attitudes and priorities of the very young and British born, which have higher significance for long term planning and decision making.

$* * * * * * * * * * * * * * * * * * * * * *$

\section{Acknowledgements}

Thank you to the University of Leicester for the study-leave which enabled the lead author to work on this paper.

Thank you to the Nottingham City Children Services Team for their support while working on this project. Most importantly, thank you to all the research participants for their contributions to the study. 


\section{$\underline{\text { References }}$}

Abbas, T. (2006) Muslims in Birmingham, UK. Background paper for the University of Oxford Centre on Migration Policy and Society.

Ahmed, A. S. (1992) Post-Modernism and Islam: Predicament and Promise. London, Routledge.

Ahmed, F. (2001) Modern Traditions? British Muslim women and Academic Achievement. Gender and Education; 13(2) 137-152.

Ahmed, L. (1992) Women and Gender in Islam: Historical Roots of a Modern Debate. Yale University Press.

Al-Ghazali, H. (1995) On Disciplining the Soul. The Islamic Texts Society: Cambridge.

Al-Hibri, A. (ed) (1982) Women and Islam. Oxford: Pergamon Press. Published as a special issue of Women's Studies International Forum: Vol 5, No 2.

Ali, R. E. (1996) The Youth Service and the Young Asians in Peterborough. Unpublished PhD Thesis, University of Nottingham; England.

Anwar, M. and Bakhsh, Q. (2002) State Policies Towards Muslims In Britain; A Research Report. Centre for Research in Ethnic Relations; University of Warwick.

Anwar, M. (1978) Between two cultures: a study of relationships between generations in the Asian community in Britain. London: Commission for Racial Equality.

Bagguley, P. and Hussain, Y. (2007) The Role of Higher Education in Providing Opportunities for South Asian Women. Joseph Rowntree Foundation; April 2007. http//www.jrf.org.uk/bookshop/eBooks/1997-education-ethnicity-poverty.pdf

Baker, D. (2002) Good Intentions: An Experiment in Middle School Single-Sex Science and Mathematics Classrooms with High Minority Enrolment. Journal of 
Women and Minorities in Science and Engineering, vol. 8, Issue 1, p.10.

Ball, S. J. (1994) Educational Reform: A critical and post-structural approach, London, Routledge.

Basit, T. N. (1995) "“I want to go to college": British Muslim Girls and the Academic Dimension of Schooling'. Muslim Education Quarterly: Vol 12, No 3: pp 36-54.

Belenky, F. M. et el (1986) Women's Ways of Knowing: The Development of Self, Voice, and Mind. New York: Basic Books.

Bemmelen, S. van and Vliet, M. van (1985) Coeducation Versus Single-Sex Schooling: a comparison between Western and Third World perspectives. The Hague. CESO.

Birmingham City Council (2005) Examination Results, 2003 - Closing Equality Gaps: results analysis by ethnicity and gender. Birmingham City Council Research and Statistics.

Deem, R. (ed) 1984, Co-education reconsidered. Milton Keynes: Open University Press.

DFES (2004) National Curriculum Assessment and GCSE/GNVQ Attainment by Pupil Characteristics in England, 2002 (Final) and 2003 (Provisional). London: DES; available online, www.dfes.gov.uk/rsgateway/DB/SFR/

Equalities Impact Assessment (2005) Manning School Impact Assessment by Archer, C. et al. 13/06/05 http://www.nottinghamcity.gov.uk/eia_bsf-manning_school_summary.doc

Foucault, M. (1980) Power/Knowledge: Selected Interviews and Other Writings, (1972-1977) /Gorden, C. Brighton: Harvester Press.

Granleese, J., \& Joseph, S. (1993). Self-perception profile of adolescent girls at a single-sex and a mixed-sex school. Journal of Genetic Psychology, 60, 210. 
Griffin, R. (ed) Education in the Muslim World Different Perspectives. Symposium Books.

Harker, R. (2000) Achievement, Gender and the Single-Sex/Co-ed Debate. British Journal of Sociology of Education, Vol. 21, No. 2 (Jun., 2000), pp. 203-218.

Harker, R., \& Nash, R. (1997, March) School Type and Education of Girls: Co-Ed or Girls Only? Paper presented at the annual meeting of the American Educational Research Association, Chicago. ED 410633.

Haw, K. (1998) Educating Muslim Girls: Shifting Discourses. Open University Press.

Hewer, C. (2001) 'Schools for Muslims'. Oxford Review of Education; 27(4) 515527.

Ivinson, G. and Murphy, P. (2007) Rethinking single sex teaching. Maidenhead: Open University Press, 2007.

Jackson, C. (2002) Can Single-Sex Classes in Co-Educational Schools Enhance the Learning Experiences of Girls and/or Boys? An Exploration of Pupils' Perceptions British Educational Research Journal, Vol. 28, No. 1 (Feb., 2002), pp. 37-48.

Kenway, J., Willis, S. with J. Blackmore and L. Rennie (1998) Answering back: girls, boys, and feminism in schools. London : Routledge.

Lee, V. E., \& Lockheed, M. M. (1990). The effects of single-sex schooling on achievement and attitudes in Nigeria. Comparative Educational Review, 34(2), 209-231. EJ 412239.

Lee, V. E., \& Marks, H. M. (1990) Sustained Effects of the Single-Sex Secondary School Experience on Attitudes, Behaviors, and Sex Differences. Journal of Educational Psychology, 82(3), 588.

LePore, P. C., \& Warren, J. R. (1997). A comparison of single-sex and co-educational Catholic secondary schooling: Evidence from the National Educational Longitudinal Study of 1988. American Educational Research Journal, 34(3), 485511. EJ 551431. 
Mernissi, F. (1985) Beyond the Veil: male-female dynamics in modern Muslim society. London: Al Saqi.

Mernissi, F. (1991) Women and Islam: A Historical Enquiry. Basil Blackwell. Oxford.

Mernissi, F. (1993) The Forgotten Queens of Islam. Polity Press, Cambridge.

Research Report (2006) Single-Gender Group Project in Pembroke School. Final Report September 2006; Pembroke School.

Riordan, C. (1990). Single-gender schools: Outcomes for African and Hispanic Americans, in Research in the Sociology of Education and Socialization; Vol. 18; pp 177-205. Greenwich, CT: JAI Press.

Riordan, C. (2004) Equality and Achievement: An Introduction to the Sociology of Education (2E). Upper Saddle River, NJ. Prentice Hall.

Shah, S. (1998) 'Researching the Roots ...' in K. Haw (1998) Educating Muslim Girls: Shifting Discourses. Open University Press; chapter two.

Shah, S. (1999) Education Management: braving boundaries. National Book Foundation; Islamabad: Pakistan.

Shah, S. (2006a) 'Leading Multiethnic Schools: a new understanding of Muslim Youth Identity'. Journal of Educational Management, Administration and Leadership; Special Edition on Leadership and Diversity; 34(2) 215-237.

Shah, S. (2006b) 'Educational Leadership: an Islamic perspective'. British Educational Research Journal, 32(3)363-385.

Shah, S. (2008) 'Leading Multi-ethnic Schools: adjustments in concepts and practices for engaging with diversity'. British Journal of Sociology of Education, 29(5).

Shah, S. (forthcoming, 2009) 'Muslim Learners in English schools: a challenge for school leaders', Oxford Review of Education; 35(4). 
Shain, F. (2003) The Schooling and Identity of Asian Girls. Trentham Books.

Sharma, U. (1980) Women, Work and Property in North-West India. London: Tavistock Publications.

Shaw, A. (1988) A Pakistani Community in Britain. Oxford: Basil Blackwell.

Single-Sex Education Report (2007) A Study by Nottingham City Council. Report online: http://www.nottinghamcity.gov.uk/single_sex_study_sg.pdf

Skelton, C., Francis, B. and Valkanova, Y. (2007) Breaking down the stereotypes: gender and achievement in schools. Working Paper Series No.59. Equal Opportunities Commission.

Smith, J. (1987) 'Islam', in A. Sharma (ed) Women In World Religions; introduction by Katherine K Young. Albany: State University of New York Press, 1987; pp 236-250.

Smithers, A. and Robinson, P. (2006) The Paradox Of Single-Sex And CoEducational Schooling. Presented at Headmasters' and Headmistresses' Conference, July 2006. Centre for Education and Employment Research, University of Buckingham.

Sullivan, A. (2006) Academic self-concept, gender and single-sex schooling in the 1970 British Cohort Study, CLS Working Paper, London: Centre for Longitudinal Studies.

The Standards Site (2006) Single-sex teaching.

http://www.standards.dfes.gov.uk/genderandachievement/understanding/singlesex I Accessed on 20.09.06.

Tomlinson, S. (1991) 'Ethnicity and Educational Attainment in England: An Overview'. Anthropology \& Education Quarterly; Vol. 22, No. 2.

Tyrer, D. and Ahmad, F. (2006) Muslim Women And Higher Education: Identities, Experiences And Prospects; A Summary Report. Liverpool John Moores University and European Social Fund. 
Weiner, G. (1994) Feminisms in education : an introduction. Buckingham: Open University Press.

Weiss, A. M. (1994) 'Challenges for a Muslim Woman in a Postmodern World', in A. S. Ahmed and D. Hastings (eds) op cited; pp 127-140.

Westwood, S. (1991) 'Power/Knowledge: The Politics of Transformative Research', in Convergence, Vol xxiv, No 3, 1991; pp 79-85.

Younger M.; Warrington M. (2002) Single-sex Teaching in a Co-educational Comprehensive School in England: an evaluation based upon students" performance and classroom interactions. British Educational Research Journal, Volume 28, Number 3, pp. 353-374.

\footnotetext{
${ }^{1}$ Single-sex education in public schools has been almost illegal in USA since the passage of Title IX of the Education Amendments of 1972.

2 The Research Project was funded by Nottingham City Council, Children's Services, and the data collection was carried out by Catherine Conchar, while the report was compiled by the lead author. Report online: www.nottinghamcity.gov.uk/education

${ }^{3}$ In keeping with the research ethics, the ethnicity of the group is not mentioned. However, the important point is that this table reflects similar attitudes across different ethnic groups of Muslim faith.

${ }^{4}$ The detailed instructions in this regard are made explicit in the fourth Sura of the Qur'an named 'al-Nisa' (woman).

${ }^{5}$ Ummah is the overarching concept used for wider Muslim community, operative beyond geo-political bounds. The root word of Ummah is umm which means 'mother' in Arabic (Ahmed, L., 1992). Commonly, this term is used among Muslims to convey the fact that all Muslims the world over constitute one community. The significance of the concept can be recongised from the fact that there are sixty-four occurrences of the term Ummah in the Quran.
} 